\title{
Prevalence of cardiovascular abnormalities in obese adults referred for bariatric weight loss surgery
}

\author{
Tendoh Timoh ${ }^{1,2^{*}}$, Rishikesh Dalal ${ }^{3}$, Saleem Ali $^{3}$, Manish Parikh ${ }^{3}$, Monvadi B Srichai ${ }^{1}$ \\ From 18th Annual SCMR Scientific Sessions \\ Nice, France. 4-7 February 2015
}

\section{Background}

Obesity is associated with increased risk of death that may be related to underlying structural and functional changes in the heart. Cardiac MR (CMR) can provide detailed structural and functional information about the heart and vasculature that may improve our understanding of obesity related cardiac morbidity and mortality.

\section{Methods}

A cohort of 77 obese patients referred for stress CMR for evaluation of dyspnea prior to weight-loss surgery (WLS) were identified from our research registry. All patients underwent standard vasodilator stress perfusion protocol with late gadolinium enhancement (LGE) imaging on a $1.5 \mathrm{~T}$ MR system. We collected demographic

Table 1 Summary data of LV and RV indices compared to normative derived data* (mean \pm SD, 95\% confidence interval)

\begin{tabular}{|c|c|c|}
\hline Categories & Obese Cohort $(n=77)$ & Normal* $(n=120)$ \\
\hline Age (years) & $48.7 \pm 2.5(22,72)$ & 20 - 79 years (equally split in each decile) \\
\hline Gender & 51 female (66\%) & 60 female $(50 \%)$ \\
\hline Body Mass Index (kg/m2) & $48.1 \pm 1.8(35.5,72)$ & \\
\hline Body Surface Area (Dubois, m2) & $2.3 \pm 0.1(1.8,3)$ & \\
\hline LVEDV (mL) & $165 \pm 9.1(95,344)$ & $142 \pm 21(102,183)$ \\
\hline LVEDV/BSA (mL/m2) & $71.3 \pm 2.9(45,127)$ & $78 \pm 8.8(60,95)$ \\
\hline LVESV (mL) & $64.6 \pm 7(23,254)$ & $47 \pm 10(27,68)$ \\
\hline LVESV/BSA (mL/m2) & $27.7 \pm 2.5(12,94)$ & $26 \pm 5.1(16,36)$ \\
\hline LVEF (\%) & $62.4 \pm 1.9(26,83)$ & $67 \pm 4.6(58,76)$ \\
\hline RVEDV (mL) & $174 \pm 10.4(76,295)$ & $144 \pm 23(98,190)$ \\
\hline RVEDV/BSA (mL/m2) & $75 \pm 3.4(42,123)$ & $78 \pm 11(57,99)$ \\
\hline RVESV (mL) & $72.2 \pm 5.9(23,168)$ & $50 \pm 14(22,78)$ \\
\hline RVESV/BSA (mL/m2) & $31.1 \pm 2.1(12,62)$ & $27 \pm 7(13,41)$ \\
\hline RVEF (\%) & $59.1 \pm 1.6(40,75)$ & $66 \pm 6(54,78)$ \\
\hline Abnormal LV diastolic function & $>21 \%$ & \\
\hline Ischemia on stress perfusion & $38 / 77(49 \%)$ & \\
\hline - Subendocardial ischemia & $34 / 77(44 \%)$ & \\
\hline LV mass (grams) & $145 \pm 10.6(70,276)$ & $127 \pm 19(90,164)$ \\
\hline
\end{tabular}

${ }^{*}$ Comparison made to published age, gender, and height matched normal weight controls.

LV, left ventricle; RV, right ventricle; EDV, end-diastolic volume; ESV, end-systolic volume; EF, ejection fraction.

${ }^{1}$ Cardiology, Medstar Georgetown University Hospital, Washington, DC, USA

Full list of author information is available at the end of the article

(c) 2015 Timoh et al; licensee BioMed Central Ltd. This is an Open Access article distributed under the terms of the Creative Commons Attribution License (http://creativecommons.org/licenses/by/4.0), which permits unrestricted use, distribution, and reproduction in any medium, provided the original work is properly cited. The Creative Commons Public Domain Dedication waiver (http:// creativecommons.org/publicdomain/zero/1.0/) applies to the data made available in this article, unless otherwise stated. 
and CMR data including ventricular volumes, global and regional functional indices, and results of stress and LGE imaging. Comparison of CMR was made to previously derived and universally accepted normative data. The goal will be to assess these parameters 1 year post WLS and analyze the structural, functional and microvascular changes.

\section{Results}

Please see table 1.

\section{Conclusions}

Multiple cardiovascular abnormalities are noted in severely obese patients including LV and RV dilation and microvascular ischemia that may contribute to the increased cardiovascular morbidity and mortality observed in this population.

\section{Funding}

Empire Clinical Research Investigator Program (ECRIP).

\section{Authors' details}

'Cardiology, Medstar Georgetown University Hospital, Washington, DC, USA.

${ }^{2}$ Cardiology, Medstar Washington Hospital Center, Washington, DC, USA.

${ }^{3}$ NYU Langone Medical Center, New York, NY, USA.

Published: 3 February 2015

doi:10.1186/1532-429X-17-S1-P188

Cite this article as: Timoh et al:: Prevalence of cardiovascular

abnormalities in obese adults referred for bariatric weight loss surgery.

Journal of Cardiovascular Magnetic Resonance 2015 17(Suppl 1):P188.
Submit your next manuscript to BioMed Central and take full advantage of:

- Convenient online submission

- Thorough peer review

- No space constraints or color figure charges

- Immediate publication on acceptance

- Inclusion in PubMed, CAS, Scopus and Google Scholar

- Research which is freely available for redistribution

Submit your manuscript at www.biomedcentral.com/submit
C Biomed Central 